\title{
Comparison of the Electromyographic Activity of the Tibialis Anterior and Isometric Dorsiflexor Strength during Dorsiflexion According to Toe Postures in Individuals with Ankle Dorsiflexor Weakness
}

\author{
In-Cheol Jeon
}

Department of Physical Therapy, College of Life and Health Science, Hoseo University, Research Institute for Basic Sciences, Hoseo University, Asan, Republic of Korea

Purpose: This study compared the electromyographic activity of the tibialis anterior (TA) and isometric dorsiflexor strength during dorsiflexion according to the toe postures in individuals with ankle dorsiflexor weakness.

Methods: Twenty subjects with ankle dorsiflexor weakness participated in this study. The electromyographic activity of the TA and isometric dorsiflexor strength during dorsiflexion between with toe flexion, extension, and neutral postures were measured using an electromyography device and a hand-held dynamometer in individuals with ankle dorsiflexor weakness. One-way repeated measured analysis of variance, and a Bonferroni post hoc test was used. The level of statistical significance was set to $a=0.01$.

Results: The electromyographic activity of the TA was greater with toe flexion during dorsiflexion than with toe extension and neutral postures $(p<0.01)$. The isometric dorsiflexor strength was smaller with toe flexion during dorsiflexion than with toe extension and neutral postures $(\mathrm{p}<0.01)$.

Conclusions: In individuals with ankle dorsiflexor weakness, the dorsiflexion with toe flexion can help improve the TA electromyographic activity. The toe posture during dorsiflexion for selective TA activation should be considered, especially in individuals with ankle dorsiflexor weakness.

Keywords: Dorsiflexor weakness, Tibialis anterior, Toe postures, Isometric dorsiflexor strength.

\section{서 론}

발등굽힘근의 정상적인 근력은 걷기, 뛰기 등 일상생활과 더불어 다 양한 스포츠 활동을 하기 위해서 필수적이다.1,2 발등굽힘근 약화 (Ankle dorsiflexor weakness)는 걷기 속도의 감소, 계단 오르기 제한 그 리고 기능적인 활동 제한에 아주 밀접한 연관이 있다.2,3특히, 이러한 발등굽힘근 약화는 신경근육계 손상과 노화로 인해 기능적 발목관 절 운동과 균형 능력을 유지하기 위해서 정확히 평가하고, 관리해야 한다. ${ }^{4}$ 선행연구를 통해 밝혀진 것은 하지를 구성하는 다양한 근육군 (엉덩관절 굽힘근/폄근/벌림근/모음근, 무릎관절 굽힘근/폄근 그리고 발등굽힘근/발바닥굽힘근)의 근력측정 실험에서 발등굽힘근 약화 가 노인낙상의 가장 효과적이고, 정확한 예측요소(predictor)라는 것 이다. 결과적으로 감소된 발목관절의 발등굽힘근의 정확한 근력측
정은 노인계층에서 낙상과 기능제한을 예상할 수 있는 요소로써 사 용될 수 있다. ${ }^{6}$

앞정강근(tibialis anterior, $\mathrm{TA}$ )근육은 발목과 무릎 관절 구조에서 필수적인 요소로써, 발등굽힘을 할 때 주동근 역할을 한다. 뛰기 및 점프를 하는 동안에 발목관절에서 동적 안정화 기능을 한다.7.8 또한, $\mathrm{TA}$ 근육은 발등굽힘을 하는 동안 발목관절의 축(axis)을 일정하게 유 지하는데 도움을 주는 역할을 한다. ${ }^{78}$ 따라서 $\mathrm{TA}$ 근육의 선택적 강화 운동은 효과적인 발목 재활의 주요 요소 중 하나라고 볼 수 있다. 선 행연구에서 TA 근육 약화는 선 자세나, 보행 중에 발의 안정성을 많 이 떨어뜨릴 수 있는 위험요소라고 정의했다. ${ }^{5,6}$ 발목과 발 구조의 이 러한 손상은 TA, 긴엄지폄근(extensor hallucis longus, EHL) 및 긴발가 락폄근(extensor digitorum longus, $\mathrm{EDL}$ ) 근육 간의 근육 불균형(muscle imbalance)에 의해 영향을 받을 수 있다. 발목의 움직임에서 발등 
굽힘의 능력은 $\mathrm{TA}$ 의 $55 \%, \mathrm{EDL}$ 의 $30 \%$ 그리고 $\mathrm{EHL}$ 의 $15 \%$ 가 기여한 다. 순수한 발등굽힘을 수행하는 근육으로써, TA 근육은 EHL 및 $\mathrm{EDL}$ 과 같은 다른 협력근에 비교하여 더 강한 것이 필요하다.10.11

$\mathrm{TA}$ 근육에 비해 우세적인 $\mathrm{EHL}$ 및 $\mathrm{EDL}$ 근육은 발목 불안정성에 영 향을 줄 수 있고, 발목 관절의 운동 전략을 변경하여 발가락 기형을 초래할 수 있다. ${ }^{12-14} \mathrm{EHL}$ 과 $\mathrm{EDL}$ 에 비해 $\mathrm{TA}$ 근육의 불충분한 근력은 발등굽힘을 하는 동안 발목관절에서 빈번하고, 과도한 보상작용을 일으키고, 이것은 발목의 불안정성(ankle instability)과 망치발가락 (hammer toe)을 야기한다.15 망치발가락은 발허리발가락관절(metatarsophalangeal joint)의 우세적이고, 보상적으로 발생되는 폄과 발가 락뼈사이관절(interphalangeal joints)의 굽힘으로 인해 유발될 수 있으 며, 엄지발가락 관절에서의 벌림으로 인해서 무지외반증이 발생될 수도 있다.7.15 협력근 우세현상(synergist dominance)은 TA 근육 약화 가 있는 대상자가 일상생활 속에서 기능적으로 필요한 발목관절 운 동에 요구되는 발등굽힘 동작을 보상하기 위해 TA 근육보다 EHL과 $\mathrm{EDL}$ 의 근육에 더 의존하는 현상이다. ${ }^{1,2}$ 이러한 $\mathrm{EHL}$ 과 $\mathrm{EDL}$ 의 근육 우세 현상은 점진적으로 $\mathrm{TA}$ 사용 감소를 가져오게 되고, 결과적으로 $\mathrm{TA}$ 근육 약화로 이어짐으로써, 순수한 발등굽힘근의 부재를 발생시 킨다. TA, EHL과 EDL의 근육 사이의 불균형(muscle imbalance)은 외 재근과 내재근 사이의 근육 불균형을 발생시키고, 발가락 변형이 악 화된다. ${ }^{2}$

외인성 발가락 폄근(extrinsic toe extensors)은 발등굽힘 동안 발가 락 굽힘을 통해서 효과적으로 억제 될 수 있다. 발가락 굽힘 운동이 발목관절과 발을 위한 효과적인 운동이라고 언급했다. ${ }^{8,10} \mathrm{EHL}$ 과 $\mathrm{EDL}$ 근육 우세 현상이나, $\mathrm{TA}$ 근육 약화가 있는 대상자가 발등굽힘을 수행하는 동안, 능동적 발가락 굽힘 운동은 $\mathrm{EHL}$ 과 $\mathrm{EDL}$ 의 근활성도 를 감소시키고, $\mathrm{TA}$ 근활성도를 증가시킬 수 있다라고 밝혔다.1,7.8 지금 까지의 대부분의 연구는 건강한 대상자로 하여 발등굽힘 근육강화 운동의 유형, 근력 및 시간에 중점을 두었다. ${ }^{16} \mathrm{TA}$ 근육 약화가 있는 대상자가 발가락 굽힘 및 폄 그리고 중립 자세에 따른 발등굽힘 동안 $\mathrm{TA}$ 근활성도 및 발등굽힘 근력의 비교 연구는 조사되지 않았다.

따라서, 본 연구의 목적은 $\mathrm{TA}$ 근육 약화가 있는 대상자가 발등굽 힘 동안 발가락 굽힘 및 폄 그리고 중립 자세를 수행하는 것이 TA 근 활성도 및 발등굽힘 근력에 미치는 영향을 비교하는 것이다. 연구 가 설은 $\mathrm{TA}$ 근육 약화가 있는 대상자가 발가락 굽힌 채 발등굽힘을 하 는 것이 발가락 중립자세 및 발가락 편 채 발등굽힘을 하는 것에 비 교하여 $\mathrm{TA}$ 근활성도에 차이가 있을 것으로 설정하였다. 반대로, $\mathrm{TA}$ 근육 약화가 있는 대상자가 발가락 굽힌 채 발등굽힘을 하는 것이 발 가락 중립자세 및 발가락 편 채 발등굽힘을 하는 것에 비교하여 등척 성 발등굽힘 근력에 차이가 있을 것으로 설정하였다.

\section{연구 방법}

\section{1. 연구대상}

$\mathrm{G}^{\star}$ Power 소프트웨어 ver. 3.1.2(Franz Faul, University of Kiel, Kiel, Germany)를 이용하여 5명의 대상자에 대한 파일럿 테스트를 진행하였 다. 표본 크기는 검정력(0.80), 알파 수준(0.05) 및 효과 크기(1.34)로 계 산되었다. 샘플 크기는 최소 11 명이상의 대상자가 필요했다. 이 연구 에서는 대상자 탈락을 고려해 20명의 TA 근육 약화가 있는 대상자가 모집되었다(Lt TA weakness 10명, Rt TA weakness 10명). 대상자들은 평균적으로 나이: $24.4 \pm 2.4$ 세, 체중: $67.5 \pm 7.4 \mathrm{~kg}$, 신장: $172.4 \pm 9.5 \mathrm{~cm}$, 남성 11 명, 여성 9 명의 조건을 가지고 있었다. 포함기준은 다음과 같 다. 1) 발목관절 정상가동범위, 2) 발목 관절의 수술경험 없음, 3) 강한 저항을 충분히 이겨내지 못하는 등급으로써, 발등굽힘근 도수근력 검사 Good으로 정하였다. 배제 기준은 다음과 같다. 1) 감각이상을 포함한 신경학적 손상, 2) 저항에 반하여 전체 관절 가동범위 운동 불 가능(Fair), 3) 고관절, 무릎 또는 발목 병리(지난 2 년 이내), 4) 발목 골 절, 5) 실험하는 동안 신체의 어느 부위에서의 통증이 있는 자로 정하 였다. 실험 프로토콜은 대상자에게 상세하게 설명되었고, 모든 대상 자는 헬싱키 선언의 윤리적 원칙에 대한 서면 동의를 제공했다.

\section{2. 실험방법}

\section{1) 등척성 발등굽힘 근력 측정}

$\mathrm{TA}$ 근육 약화가 있는 대상자의 등척성 발등굽힘 최대근력은 앉은 자 세에서 $90^{\circ}$ 무릎 굽힘 자세에서 측정되었다. 대상자는 상체는 편안하 게 뒤쪽으로 기댄 채 측정을 진행하였다. 모든 대상자가 TA 근육 약 화가 양쪽 모두 있었지만, 약화가 좀 더 심한 쪽을 기준으로 근력을 측정하였다. 도수근력측정기(Lafayette Instrument Company, Lafayette, $\mathrm{IN}, \mathrm{USA}$ )를 이용하여 등척성 발등굽힘 근력을 측정하였다. 도수근력 측정기 $(0.1 \mathrm{~N}$ 단위)를 이용해 모든 $\mathrm{TA}$ 근육 약화가 있는 대상자의 힘 을 측정 하였다.

근력측정은 발목관절의 발바닥 굽힘 방향으로 저항을 제공하였 고, 바깥쪽 복사뼈로부터 앞쪽 $8 \mathrm{~cm}$ 거리에 있는 발등 위를 눌러 측정 하였다. 대상자 사이에 근력측정 위치를 표준화하기 위해, 동일한 발 등 부위에 마커 표시를 하였다. 연구진행자에 의해 아래쪽 방향으로 저항이 5 초간 제공되는 동안 대상자는 발목 중립 자세로 발등굽힘근 들의 등척성 수축을 통해 유지하였고, 발가락 폄 상태에서 발등굽힘 자세를 유지했다. 그 후에, 연구진행자에 의해 아래쪽 방향으로 저항 이 5 초간 제공되는 동안 대상자는 발목 중립 자세로 발등굽힘근들의 등척성 수축을 통해 유지하였고, 발가락 굽힘 상태에서 발등굽힘 자 세를 유지했다. ${ }^{12}$ 그 후에, 연구진행자에 의해 아래쪽 방향으로 저항 이 5 초간 제공되는 동안 대상자는 발목 중립 자세로 발등굽힘근들의 
등척성 수축을 통해 유지하였고, 발가락 중립 상태에서 발등굽힘 자 세를 유지했다. 발가락 자세에 따른 측정 순서는 무작위로 진행되었 다. TA 근육 약화가 있는 대상자가 근피로를 예방하기 위한 실험동작 사이에 10 분간 휴식 시간이 충분히 제공되었고, 3 회 측정을 수행하였 다. ${ }^{17}$ 모든 데이터 값은 평균값으로 사용하였다.

\section{2) 앞정강근 근활성도 측정}

EMG-feedback (wireless EMG System 1000, BTS, Italy)을 이용해서 측정 하였다. 전용 소프트웨어를 통해 EMG 신호를 분석하는데 사용되었 다. EMG 신호는 대역 통과 필터 $(20-450 \mathrm{~Hz})$, 표본추출률 $(1,024 \mathrm{~Hz})$, 여 과필터 $(60 \mathrm{~Hz})$ 로 설정하였다. 근전도 신호는 root-mean-square (RMS) data 와 a moving window 50ms 처리되었다. 대상자가 $\mathrm{TA}$ 근육 약화가 심한 쪽을 기준으로 등척성 발등 굽힘을 유지하면서, EMG 신호를 5 초 동안 기록하였다. 발가락을 굽힌 채와 발가락을 편 채 그리고 발가 락 중립자세, 이 세 가지 조건에서 발등굽힘을 수행하면서, 등척성 수 축 단계 동안 2-4초의 EMG 신호를 분석에 사용하였다. 운동의 시작 시 1 초와 종료시 1 초는 제거하였다. ${ }^{1819}$ 피부 저항을 최소화하기 위해 근육의 피부 위는 알코올 솜으로 세척하고 전극을 부착하였다. 일회 용 $\mathrm{Ag} / \mathrm{AgCl}$ 표면 전극을 정강뼈의 중간 부위에서 $\mathrm{TA}$ 근육이 가장 두 꺼운 곳에 부착하였다..$^{20}$ 또한, 전극은 $\mathrm{TA}$ 의 근육 섬유로 $3 \mathrm{~cm}$ 평행하 게 배치되어 부착하였다. ${ }^{20} \mathrm{TA}$ 의 최대등척성근수축(maximal voluntary isometric contraction, MVIC)을 이용하여 근력을 표준화하였다. ${ }^{21}$ 앉아있는 자세에서 몸통을 뒤로 살짝 기댄 채, 발등굽힘과 안쪽번짐 을 최대한 수행한 상태에서 반대쪽 방향으로 최대한의 저항을 제공 하여 TA 근육의 MVIC 값을 산출하였다. MVIC를 측정하는 동안 EMG 신호에서 처음과 끝 1 초를 제거하였다. ${ }^{18,19} \mathrm{TA}$ 근육이 발등굽힘 최대근수축을 수행하는 것을 3 회 측정해서 MVIC의 평균값을 계산 하였고, 발가락을 굽힌 채와 발가락을 편 채 그리고 발가락 중립 자 세, 이 세 가지 조건에서 발등굽힘을 수행하면서 발생하는 EMG 신호 를 이용하여 MVIC (\%MVIC)의 백분율로 계산하여 표시하였다.

\section{3. 통계 분석}

통계분석을 위해 SPSS software ver. 18.0 (SPSS IL, Chicago)가 사용되었 다. 데이터 \pm 표준 편차로 표현되었다. Kolmogorov-Smirnov 검정을 사 용하여 수집된 데이터의 정규 분포를 확인하였다. 발가락 굽힘, 폄 그 리고 중립자세에 따른 $\mathrm{TA}$ 근육 활동과 등척성 발등굽힘 근력의 차이 에 대해 반복측정분산분석(one-way repeated measured analysis of variance) 검정을 사용하였다. 짝비교(pair-wise comparisons)를 통해 유의 수준을 조절하였다 $(0.05 / 3=0.0167)$. 통계학적 유의 수준은 0.01 로 설 정하였다.
Table 1. The difference in the electromyographic activity of the TA during dorsiflexion with toe flexion, extension and neutral postures.

$(\mathrm{N}=20)$

\begin{tabular}{|c|c|c|c|c|c|}
\hline \multirow[b]{2}{*}{ Variables } & \multicolumn{3}{|c|}{ Mean \pm SD (\%) } & \multirow[b]{2}{*}{ f-value } & \multirow[b]{2}{*}{$p$-value } \\
\hline & $\begin{array}{l}\text { Dorsiflexion } \\
\text { with toe } \\
\text { flexion }\end{array}$ & $\begin{array}{c}\text { Dorsiflexion } \\
\text { with toe } \\
\text { neutral posture }\end{array}$ & $\begin{array}{l}\text { Dorsiflexion } \\
\text { with toe } \\
\text { extension }\end{array}$ & & \\
\hline$\% \mathrm{MVIC}$ & $51.94 \pm 17.35$ & $40.12 \pm 13.74$ & $37.13 \pm 15.25$ & 7.82 & $<0.01^{*}$ \\
\hline
\end{tabular}

Values represent mean ( \pm standard deviation), ${ }^{*} \mathrm{p}<0.01$ by One-way repeated analysis of variance.

Table 2. The difference in the isometric dorsiflexor strength during dorsiflexion with toe flexion, extension and neutral postures.

$(N=20)$

\begin{tabular}{|c|c|c|c|c|c|}
\hline \multirow[b]{2}{*}{ Variables } & \multicolumn{3}{|c|}{ Mean $\pm S D(k g)$} & \multirow[b]{2}{*}{ t-value } & \multirow[b]{2}{*}{ p-value } \\
\hline & $\begin{array}{l}\text { Dorsiflexion } \\
\text { with toe } \\
\text { flexion }\end{array}$ & $\begin{array}{c}\text { Dorsiflexion } \\
\text { with toe } \\
\text { neutral posture }\end{array}$ & $\begin{array}{c}\text { Dorsiflexion } \\
\text { with toe } \\
\text { extension }\end{array}$ & & \\
\hline Strength & $14.24 \pm 10.03$ & $20.35 \pm 6.15$ & $25.15 \pm 13.13$ & 5.22 & $<0.01^{*}$ \\
\hline
\end{tabular}

Values represent mean ( \pm standard deviation), ${ }^{*} p<0.01$ by One-way repeated analysis of variance.

\section{결 과}

$\mathrm{TA}$ 근활성도와 등척성 발등굽힘 근력에 대한 모든 데이터는 정규분 포하였다( $\mathrm{p}>0.05)$. TA 근활성도와 등척성 발등굽힘 근력은 발가락 자세(발가락 굽힌 채 발등 굽힘 vs 발가락 편 채 발등 굽힘 vs 발가락 중립자세에서 발등 굽힘)에 따라 통계학적인 유의한 차이가 있었다 $(\mathrm{p}<0.01)$ (Tables 1, 2). 발가락 굽힌 채 발등굽힘 할 때의 TA 근활성도는 발가락을 편 채 그리고 발가락 중립자세에서 발등 굽힘 할 때 보다 유 의하게 높았다 $(\mathrm{p}<0.01)$ (Table 1). 발가락 굽힌 채 발등굽힘을 할 때의 등척성 발등굽힘 근력은 발가락을 편 채 그리고 발가락 중립자세에 서 발등 굽힘 할 때 보다 유의하게 낮았다( $\mathrm{p}<0.01)$ (Table 2).

$\mathrm{TA}$ 근활성도와 등척성 발등굽힘 근력에서 발가락을 편 채 그리고 발가락 중립자세에서 발등 굽힘 할 때 두 조건 사이에 유의한 차이는 없었다 $(\mathrm{p}>0.01)$.

\section{고 찰}

이 연구의 목적은 TA 근육 약화가 있는 대상자의 발가락 자세에 따 라 발등굽힘을 수행하는 동안 TA 근활성도와 등척성 발등굽힘 근력 을 비교하는 것이다. 이 연구의 결과는 $\mathrm{TA}$ 근육 약화가 있는 대상자 가 발가락 굽힌 채 발등굽힘 동안 $\mathrm{TA}$ 근활성도가 발가락을 편 채 그 리고 발가락 중립자세에서 발등굽힘 할 때 보다 유의한 증가를 보였 다. $14.81 \%$ 증가, $11.82 \%$ 증가). 반대로 TA 근육 약화가 있는 대상자가 발가락 굽힌 채 발등굽힘 동안 등척성 발등굽힘 근력이 발가락을 편 
채 그리고 발가락 중립자세에서 발등굽힘 할 때 보다 유의한 감소를 보였다(10.91 kg 감소, $5.11 \mathrm{~kg}$ 감소). 이 연구 결과에 따르면, TA 근육 약 화가 있는 대상자가 발가락 굽힌 채 발등굽힘 동안 등척성 발등굽힘 근력이 발가락을 편 채 그리고 발가락 중립자세에서 발등굽힘 할 때 보다 작았지만, 발가락 굽힌 채 발등굽힘 동안 $\mathrm{TA}$ 근활성도가 발가 락을 편 채 그리고 발가락 중립자세에서 발등굽힘 할 때 보다 유의한 증가를 보였다는 것이다.

이러한 연구결과를 설명하기 위한 이유는 다음과 같다. 첫째, 협력 근 우세현상(synergist dominance)으로 설명될 수 있다. TA 근육 약화 가 있는 대상자가 발등굽힘 동작을 수행하면서 요구되는 근력을 보 상하기 위해서 $\mathrm{EHL}$ 과 $\mathrm{EDL}$ 의 근육수축에 의존한다는 것이다. TA 근 육 약화가 있는 대상자의 등척성 발등굽힘 근력은 발등굽힘 동작을 위해 협력근들과 같이 작용함으로써, TA, $\mathrm{EHL}$ 및 $\mathrm{EDL}$ 과 같은 다양 한 근육에 의해 등척성 발등굽힘 근력이 형성된다. 또한, 등척성 발등 굽힘 근력의 증가는 발가락을 편 채 $\mathrm{TA}, \mathrm{EDL}$ 및 $\mathrm{EHL}$ 근육들이 공동 활성화(co-activation)되기 때문이다. 따라서, TA 근육 약화가 있는 대 상자가 발등굽힘을 수행할 때 $\mathrm{EHL}$ 및 $\mathrm{EDL}$ 을 협력근으로써 근력 참 여를 유도하기 위해 발가락 폄 자세가 보상작용으로 일어날 수 있다. 발가락 폄 자세가 동반됨에 따라 $\mathrm{EHL}$ 및 $\mathrm{EDL}$ 근수축을 유발하여 발 등굽힘 근력을 보완시키는 보상작용이라고 할 수 있으며, 이러한 보 상작용이 계속된다면, TA 근육 약화 증상을 더욱 악화시킬 수 있다. 등척성 발등굽힘을 주기능으로 하는 TA 근육의 선택적 강화운동은 보조협력근인 $\mathrm{EHL}$ 및 $\mathrm{EDL}$ 의 동시 활성화 없이 훈련하는 것이 필수 적이다. 7,810 따라서, 발등굽힘 동안 $\mathrm{TA}$ 의 근활성도 증가와 $\mathrm{EDL}$ 및 $\mathrm{EHL}$ 의 근활성도 감소를 위해 발가락 자세를 굽힘 채로 수행하는 것 이 $\mathrm{TA}, \mathrm{EDL}$ 및 $\mathrm{EHL}$ 근육 사이의 선택적 근육 운동이 가능하고, 이것 이 각 근육 간의 균형을 최적화하기 위해 필요하다고 볼 수 있다.8. 선 택적 $\mathrm{TA}$ 근육 강화운동을 통해서, 발등굽힘 근력의 $50 \%$ 이상은 $\mathrm{TA}$ 근육이 참여할 수 있어야 해당 근육이 발등굽힘 주동근으로써 효과 적으로 기능 수행을 할 수 있다. 이와는 반대로, 등척성 발등굽힘 근 력의 감소는 발가락을 굽힌 채 수행할 때 일어났다. 발가락을 굽힌 채 발등굽힘 할 때는 $\mathrm{TA}$ 근육을 활성화되는 반면에, $\mathrm{EHL}$ 및 $\mathrm{EDL}$ 근육 은 발가락 굽힘 동작으로 인해서 억제(muscle inhibition)되기 때문에 발등굽힘 근력에 기여할 수 있는 정도가 제한적이다. 실제로 자발적 근육수축 활성화(volitional active muscle contractions)는 상호 억제 메 커니즘(reciprocal inhibition mechanism)을 통해 근육의 활성화를 균 형적으로 조절할 수 있다.8. 등척성 발등굽힘 동안 능동적 발가락 굽 힘으로 인해 $\mathrm{EHL}$ 및 $\mathrm{EDL}$ 근육이 신장된 상태가 되기 때문에, 자발적 으로 유도된 억제(volitionally induced inhibition)가 일어났고, 이것이 $\mathrm{EHL}$ 및 EDL 근육 비활성화에 기여할 수 있다.22,23 이러한 구성요소는 특히 TA 근육 약화로 인해서 EHL와 EDL 근육 우세를 가진 대상자
를 위해서 발등굽힘 하는 동안 선택적 근육 강화 운동을 위해 상당 히 효과적이라고 볼수 있다.

둘째, $\mathrm{EHL}$ 및 $\mathrm{EDL}$ 근육이 등척성 발등굽힘 동안 발가락 폄에 의해 서 단축된 위치에 있음으로써, 길이-장력 관계에 의해 해당근육들이 더 큰 장력을 형성하게 된다는 것이다. 7.824 반대로, 발가락을 굽힌 채 등척성 발등굽힘 하는 것은 $\mathrm{EHL}$ 및 $\mathrm{EDL}$ 근육들이 신장된 상태가 되 기 때문에, 이러한 근육들은 감소된 장력에 의해서 근활성도가 억제 되었다고 볼 수 있다. $7{ }^{8.8}$ 따라서 발가락 굽힌 채 발등 굽힘 동안 관찰된 $\mathrm{TA}$ 근활성도의 증가는 $\mathrm{EHL}$ 및 $\mathrm{EDL}$ 근육의 억제에 의해서 형성되었 다고 볼 수 있다. EHL과 $\mathrm{EDL}$ 근육은 발가락을 편 채 발등굽힘을 하 게 되면 더 큰 장력으로 인해서 등척성 발등굽힘 근력에 더 기인 할 수 있게 되지만, 반면에 TA 근육이 약화된 대상자에게는 전체적 발 등굽힘 근력 측정에 있어서 $\mathrm{TA}$ 근육이 기여하는 비율을 더욱 감소된 상태가 된다. ${ }^{25}$ 이러한 요소들은 등척성 발등굽힘 동안 발가락 굽힘 및 폄 자세가 $\mathrm{TA}, \mathrm{EHL}$ 및 $\mathrm{EDL}$ 근육 사이의 선택적 근육 활성화에 영 향을 줄 수 있음을 암시한다. 따라서 $\mathrm{TA}$ 근육 약화가 있는 대상자에 게는 특히 TA, $\mathrm{EHL}$ 및 $\mathrm{EDL}$ 근육 균형을 고려하기 위하여, 발가락 굽 힌 채 발등 굽힘 운동을 수행하면, $\mathrm{EHL}$ 및 $\mathrm{EDL}$ 의 근활성도를 적절하 게 억제하고, $\mathrm{TA}$ 의 근활성도를 효과적으로 증가시킴으로써, 선택적 $\mathrm{TA}$ 근육 강화 운동이 가능하다.

마지막으로, 등척성 발등굽힘을 수행하면서 발가락 중립 자세에 서 수행하는 것은 발가락 폄 자세에서 수행하는 것보다 $\mathrm{TA}$ 근활성도 와 등척성 발등굽힘 근력에 유의한 차이를 보이지 않았다. 이것은 $\mathrm{TA}$ 근육 약화가 있는 대상자가 발등굽힘을 수행하면서 발가락 중립자 세를 하는 것이, $\mathrm{EHL}$ 및 $\mathrm{EDL}$ 근육이 상호 억제 메커니즘(reciprocal inhibition mechanism)을 통해 근육의 활성화를 낮추는 것에 효과적 이지 않은 것으로 생각할 수 있다. 또한 발가락 중립자세에서 발등굽 힘을 수행하더라도, TA 근육이 약할 경우, $\mathrm{EHL}$ 및 $\mathrm{EDL}$ 근육의 우세 화 현상이 일어났기 때문에 $\mathrm{TA}$ 근활성도와 등척성 발등굽힘 근력에 발가락 폄 자세에서 발등굽힘을 하는 것과 차이가 없었다. 따라서, $\mathrm{TA}$ 근육 약화가 있는 대상자의 발가락 자세에 따라 발등굽힘 운동 을 수행할 때, 발가락 폄 자세 뿐만 아니라 발가락 중립 자세에서도 보상작용 현상이 발생할 수 있기 때문에 선택적인 TA 강화운동에 효 과적이지 않다는 것을 고려할 수 있다.

본 연구에는 몇 가지 제한점이 있다. 첫째 발등굽힘 동안 해당근육 에서 크로스토크가 많이 발생하였기 때문에 EHL와 EDL 근활성도 는 조사되지 않았다. 발등굽힘 동안 $\mathrm{EHL}$ 및 $\mathrm{EDL}$ 근활성도를 위한 추 가 연구가 필요하다. 둘째, 이 연구결과는 다른 발목 위치로 일반화 될 수 없다. 내전 또는 외전된 상태에서 발가락 자세에 따른 다양한 발목 관절의 자세와 발가락 자세를 고려한 $\mathrm{TA}$ 근활성도 연구가 추가로 필 요하다. 셋째, 이 연구의 결과를 발등굽힘근 도수근력검사 poor 이하 
의 환자에게는 적용할 수 없다. 추후 연구에서는 보행시 foot drop 현 상이 일어나는 신경계 손상 환자를 대상으로 추가 연구가 필요하다.

\section{REFERENCES}

1. Krause DA, Cloud BA, Forster LA et al. Measurement of ankle dorsiflexion: A comparison of active and passive techniques in multiple positions. J Sport Rehabil. 2011;20(3):333-44.

2. Tiedemann A, Sherrington C, Lord SR. Physiological and psychological predictors of walking speed in older community-dwelling people. Gerontology. 2005;51(6):390-5.

3. Keysor JJ, Dunn JE, Link CL et al. Are foot disorders associated with functional limitation and disability among community-dwelling older adults? J Aging Health. 2005; 17(6):734-52.

4. Burns J, Redmond A, Ouvrier R et al. Quantification of muscle strength and imbalance in neurogenic pes cavus, compared to health controls, using hand-held dynamometry. Foot Ankle Int. 2005;26(7):540-4.

5. PG Macrae, M Lacourse, R Moldavon. Physical performance measures that predict fall status in community-dwelling older adults. J Orthop Sports Phys Ther. 1992;16(3):123-8.

6. Spink MJ, Fotoohabadi MR, Menz HB. Foot and ankle strength assessment using hand-held dynamometry: reliability and age-related differences. Gerontology. 2010;56(6):525-32.

7. Sahrmann SA. Movement system impairment syndromes of the extremities, cervical and thoracic spines. Amsterdam, Elsevier, 2010:533-46.

8. Kisner C, Colby LA. Therapeutic Exercise: foundations and techniques. Philadelphia, FA Davis Company, 2012:764-6.

9. Franck WM, Olk A, Hennig FF. Combined rupture of the tibialis anterior and the extensor hallucis longus tendons-functional reconstruction. Arch Orthop Trauma Surg. 2005;125(4):277-80.

10. Jeon IC, Jang JH. Comparison of Tibialis Anterior Muscle Activity and Dorsiflexor Strength according to Toe Postures. JMST. 2020;4(1):13-7.

11. Hislop H, Avers D, Brown M. Daniels and Worthingham's muscle testing: Techniques of manual examination and performance testing. Philadelphia, Elsevier, 2013:283-96.

12. Page, P, Frank C, Lardner R. Assessment and treatment of muscle imbal- ance: The Janda approach. Champaign, Human Kinetics, 2010:799-800.

13. Scheck M. Etiology of acquired hammertoe deformity. Clin Orthop Relat Res. 1977;(123):63-9.

14. Hansen ST. Functional reconstruction of the foot and ankle. Philadelphia, Lippincott Williams \& Wilkins, 2000:455-62.

15. Kwon OY, Tuttle LJ, Johnson JE et al. Muscle imbalance and reduced ankle joint motion in people with hammer toe deformity. Clin Biomech. 2009;24(8):670-5.

16. Wernbom M, Augustsson J, Thomeé R. The influence of frequency, intensity, volume and mode of strength training on whole muscle crosssectional area in humans. Sports Med. 2007;37(3):225-64.

17. O'Shea S, Grafton K. The intra and inter-rater reliability of a modified weight-bearing lunge measure of ankle dorsiflexion. Man Ther. 2013;18(3):264-8.

18. Soderberg GL, Knutson LM. A guide for use and interpretation of kinesiologic electromyographic data. Phys Ther. 2000;80(5):485-98.

19. Ayotte NW, Stetts DM, Keenan G et al. Electromyographical analysis of selected lower extremity muscles during 5 unilateral weight-bearing exercises. J Orthop Sports Phys Ther. 2007;37(2):48-55.

20. Criswell E. Cram's introduction to surface electromyography. Sudbury, Jones \& Bartlett, 2010:371-3.

21. Kendall FP, McCreary EK, Provance PG et al. Muscles testing and function, with posture and pain. Baltimore, Lippincott Williams \& Wilkins, 2005:410.

22. Condon SM, Hutton RS. Soleus muscle electromyographic activity and ankle dorsiflexion range of motion during four stretching procedures. Phys Ther. 1987;67(1):24-30.

23. Sady SP, Wortman M, Blanke D. Flexibility training: Ballistic, static or proprioceptive neuromuscular facilitation. Arch Phys Med Rehabil 1982;63(6)261-3.

24. Jeon IC, Jang JH. Comparison of Prone Hip Extension Exercise and Prone Hip Extension Exercise after Iliopsoas Stretching on Lumbopelvic Control and Gluteus Maximus Activity in Subjects with Short Iliopsoas. JMST. 2017;1(1):19-25.

25. Lee JE, Park GH, Lee YS et al. A comparison of muscle activities in the lower extremity between flat and normal feet during one-leg standing. J Phys Ther Sci. 2013;25(9):1059-61. 